STUDI

FRANCESI

\section{Studi Francesi}

Rivista quadrimestrale fondata da Franco Simone

169 (LVII | I) | 2013

LA RÉVOLUTION SUR SCÈNE a cura di Pierre Frantz, Paola Perazzolo, Franco Piva

\title{
Montesquieu, Histoire véritable et autres fictions
}

\section{Olga Penke}

\section{OpenEdition}

\section{Journals}

Édition électronique

URL : http://journals.openedition.org/studifrancesi/3412

DOI : $10.4000 /$ studifrancesi.3412

ISSN : 2421-5856

Éditeur

Rosenberg \& Sellier

Édition imprimée

Date de publication : 1 avril 2013

Pagination : 173

ISSN : 0039-2944

\section{Référence électronique}

Olga Penke, « Montesquieu, Histoire véritable et autres fictions », Studi Francesi [En ligne], 169 (LVII | I) | 2013, mis en ligne le 30 novembre 2015, consulté le 18 septembre 2020. URL : http://

journals.openedition.org/studifrancesi/3412; DOI : https://doi.org/10.4000/studifrancesi.3412

Ce document a été généré automatiquement le 18 septembre 2020.

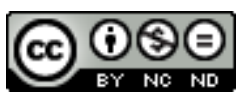

Studi Francesi è distribuita con Licenza Creative Commons Attribuzione - Non commerciale - Non opere derivate 4.0 Internazionale. 


\title{
Montesquieu, Histoire véritable et autres fictions
}

\author{
Olga Penke
}

\section{RÉFÉRENCE}

MONTESQUIEU, Histoire véritable et autres fictions. Choix et édition de Catherine volPILHACAUGER et Philip STEWART, Paris, Gallimard («Collection Folio Classique»), 2011, pp. 364.

1 Montesquieu le philosophe, l'historien et le romancier a déjà été présenté au public de la collection «Folio classique» par les Lettres persanes, les Considérations sur les Romains et l'Esprit des Lois. Les lecteurs peuvent découvrir cette fois la richesse de son œuvre fictionnelle. Les deux textes qui dominent, déjà par leur ampleur, le volume sont un roman fantaisiste: l'Histoire véritable et un conte philosophique: Arsace et Isménie. Le choix judicieux montre en même temps l'esprit scintillant de l'auteur et la variété des formes brèves de sa narration fictionnelle: bribes de pensées de ses cahiers dont il espère se servir, lettres (Lettres de Xénocrate à Phérès), dialogues (Dialogue de Sylla et d'Eucrate, Dialogue de Xantippe et de Xénocrate), anecdote (Lysimaque). L'édition destinée à un public qui cherche à la fois le plaisir de la lecture et du savoir met également en valeur quelques contes insérés dans les Lettres persanes dans le but de faire réfléchir tout en divertissant (Histoire des Troglodytes, Histoire d'Aphéridon et d'Astarté).

Deux éminents spécialistes de Montesquieu assurent une édition brillante par un texte sûr, un dossier, des variantes, une bibliographie et des notes instructives, basées sur les résultats des recherches les plus récentes, réalisées pour les éditions critiques. Le lecteur est gâté, car il peut compléter à sa guise les riches informations qui lui sont présentées dans ce livre, par le site Montesquieu, mis à sa disposition librement sur Internet. Nous y faisons connaissance avec les particularités de la composition de Montesquieu qui pense par des hypothèses et des exemples et qui réalise continuellement un dialogue avec ses sources, même quand il ne s'y réfère pas explicitement, comme dans les narrations fictionnelles. La forme plus ou moins 
dialogique de la lettre, du dialogue lui-même et d'autres genres qui mettent en scène des personnages, mènent le lecteur, par la multiplication des voix, à une participation active lors de la mise en question du rôle des institutions, des qualités du prince censées garantir les limites du pouvoir politique ou de quelques valeurs chères à l'époque comme la liberté, la sensibilité, le bonheur ou certaines vertus féminines. Les facteurs divers de sa narration fictionnelle deviennent dominants: les tropismes de l'Asie et de l'Antiquité, les modèles romanesques comme le picaresque, la stylisation du monde historique, le ton libertin ou érotique.

3 Les textes publiés dans ce volume ont été assez méconnus au xvII siècle, l'auteur n'osant pas les livrer ouvertement au public, comme les notices nous en instruisent. Ils ont sommeillé chez des amis pendant des dizaines d'années (comme l'Histoire véritable) ou ont été publiés bien après sa mort, et ils ont été ignorés par la critique pratiquement pendant deux siècles. Son "roman" le plus souvent édité et traduit en plusieurs langues clôt l'ensemble des textes (Le Temple de Gnide). Inspiré par le genre poétique de "temple" de la Renaissance, il convient à merveille à la littérature des salons. Ses sept chants évoquent les conceptions différentes de l'amour qui suggèrent de se livrer aussi bien à l'amour pudique qu'à l'amour charnel. Les contemporains et la postérité ont admiré dans ce poème en prose tant l'évocation de l'Antiquité combinée avec l'art de la jouissance que le style moderne du philosophe du "goût".

4 Pour ceux qui connaissent déjà Montesquieu et pour ceux qui le découvrent maintenant, ce volume constituera une lecture passionnante, savoureuse et instructive. 